\title{
Small gaps are preferred for the scatter hoarding of acorns by rodents
}

\author{
Fei $\mathrm{Yu}^{1}$, Shanshan $\mathrm{Wei}^{1}$, Yang Wang ${ }^{1}$, Yingchen $\mathrm{Li}^{1}$, Lixia Zhang ${ }^{1}$, Qingwei Lin ${ }^{1}$, Jianmin \\ $\mathrm{Ma}^{1}$, and Xianfeng $\mathrm{Yi}^{2}$ \\ ${ }^{1}$ Henan Normal University \\ ${ }^{2}$ Qufu Normal University
}

October 20, 2020

\begin{abstract}
In general, it is accepted that gap formation significantly affects the placement of scatter-hoarded seeds by small rodents, but the effects of different forest gap sizes on the seed-eating and scatter-hoarding behaviors of small rodents remain unclear. Thus, we examined the effects of a closed canopy forest, forest edge, and gaps with different sizes on the spatial dispersal of Quercus variabilis acorns and cache placement by small rodents using coded plastic tags in the Taihang Mountains, China. The seeds were removed rapidly and there were significant differences in the seed-eating and caching strategies between the stand types. We found that $\mathrm{Q}$. variabilis acorns were usually eaten after being removed from the closed canopy forest and forest edges. By contrast, the Q. variabilis acorns in the forest gap stands were more likely to be scatter hoarded. The dispersal distances of Q. variabilis acorns were significantly longer in the forest gap plots compared with the closed canopy and forest edge plots. However, the proportions of scatter-hoarded seeds did not increase significantly as the gap size increased. In small-scale oak reforestation projects or research, creating small gaps to promote rodent-mediated seed dispersal may effectively accelerate forest recovery and successional processes.
\end{abstract}

\section{Hosted file}

manuscript.pdf available at https://authorea.com/users/368810/articles/487832-small-gapsare-preferred-for-the-scatter-hoarding-of-acorns-by-rodents 